\title{
ATIVIDADE COLINESTERÁSICA NO PLASMA E EM ERITRÓCITOS DE PACIENTES COM AS FORMAS CARDÍACA E INDETERMINADA DA DOENÇA DE CHAGAS
}

\author{
Roseli A.S. Gomes, Lineu J. Miziara, José Geraldo F. Gonçalves, \\ Kleber G. Franchini e Valdemar Hial.
}

\begin{abstract}
A atividade colinesterásica foi determinada no plasma e em eritrócitos de 10 individuos normais e em 26 pacientes chagásicos crônicos, sendo 6 com insuficiência cardiaca congestiva compensada, 10 com cardiopatia sem insuficiência cardiaca congestiva e 10 com a forma indeterminada. Os valores enzimáticos encontrados foram (média \pm sd): $2196 \pm 442 \mathrm{UI} / \mathrm{L}$ no plasma e 19,4 $\pm 3,3 \mathrm{UI} / \mathrm{g} \mathrm{Hb}$ em eritrócitos do grupo control:; $2291 \pm 317 \mathrm{UI} / \mathrm{L}$ no plasma e 19,2 $\pm 3,7 \mathrm{UI} / \mathrm{g} \mathrm{Hb}$ em eritrócitos dos chagásicos com insuficiência cardiaca congestiva compensada; $2445 \pm 357$ UI/L no plasma e 18,3 $\pm 3,0 \mathrm{UI} / \mathrm{g} \mathrm{Hb}$ em eritrócitos dos cardiopatas chagásicos sem insuficiência cardiaca congestiva; $2006 \pm 327 \mathrm{UI} / \mathrm{L}$ no plasma e 17,8 $\pm 3,1 \mathrm{UI} / \mathrm{g} \mathrm{Hb}$ em eritrócitos de chagásicos com a forma indeterminada.

Nossos dados mostram que o comprometimento neuronal que ocorre nos cardiopatas chagásicos crônicos não é suficiente para levar a alteraçóes significativas $(p>0,05)$ das atividades colinesterásicas no plasma e em eritrócitos.
\end{abstract}

Palavras chaves: Atividade colinesterásica. Doença de Chagas. Cardiopatia chagásica. Forma indeterminada.

A atividade colinesterásica, tanto no plasma (E.C. 3.1.1.8.) como em eritrócitos (E.C. 3.1.1.7.), tem sido utilizada como parâmetro para se determinar o grau de exposição a inseticidas organofosforados 5 , assim como no auxílio diagnóstico da doença de Hirschsprung 34 .

A determinação da colinesterase no plasma tem servido ainda como indicador da capacidade de sintese da célula hepática. A atividade colinesterásica diminuida foi encontrada em hepatite aguda e cirrose hepática, ou seja, naquelas condições onde a sintese hepática de proteinas e em particular da albumina está comprometida 5111314 .

Hial e cols ${ }^{8}$ mostraram significativa redução na atividade colinesterásica no plasma e em eritrócitos de individuos com megacolo chagásico, estando em concordância com os achados de comprometimento causado pelo Trypanosoma cruzi, da inervação intrinseca do colo, expresso pela lesão neuronal ${ }^{1915}$, e das células de Schwann ${ }^{15}$.

$\mathrm{Na}$ forma crônica cardíaca da doença de Chagas não existe uma precisa correlação entre o grau de

\footnotetext{
Trabalho realizado no Departamento de Bioquímica e Biofisica e no Departamento de Medicina da Faculdade de Medicina do Triângulo Mineiro. 38100 Uberaba, MG.

Este trabalho foi realizado com auxilio financeiro do CNPq. Endereço para correspondência: Prof. Valdemar Hial, Departamento de Bioquimica e Biofísica, Faculdade de Medicina do Triângulo Mineiro, 38100 Uberaba, MG, Brasil. Recebido para publicação em 18/9/1985.
}

desnervação e a forma de expressão clínica da cardiopatia 1291215 , sugerindo que esta desnervação cardiaca não é o único fator responsável pela progressiva deterioração contrátil do coração até a insufíciência cardíaca congestiva e que a miocardite crônica deve exercer importante papel na fisiopatologia desta doença ${ }^{12}$.

Assim sendo, a exemplo do que foi feito para o megacolo chagásico ${ }^{8}$, resolvemos verificar o comportamento da atividade colinesterásica eritrocitária e plasmática de pacientes com as formas crônicas cardíaca e indeterminada da doença de Chagas.

\section{MATERIAL E MÉTODOS}

Foram estudados 10 indivíduos clinicamente normais e com reações de Guerreiro-Machado e imunofluorescência indireta para Trypanosoma cruzi negativas.

Os pacientes chagásicos, em número de 26 , todos com sorologia positiva para a doença, foram distribuidos em 3 grupos, segundo dados clínicos, radiológicos e eletrocardiográficos: 6 cardiopatas com insuficiência cardiaca congestiva compensada, 10 chagásicos cardiopatas sem evidência de insuficiência cardíaca e 10 chagásicos com a forma indeterminada da doença. Nenhum dos pacientes chagásicos apresentava manifestações clinicas e radiológicas de megacolo e/ou megaesôfago.

As amostras de sangue foram obtidas após 12 horas de jejum, em 2 frascos, um contendo EDTA e 
Gomes RAS, Miziara LJ, Gonçalves JGF, Franchini KG, Hial V. Atividade colinesterásica no plasma e em eritrócitos de pacientes com as formas cardíaca e indeterminada da doença de Chagas. Revista da Sociedade Brasileira de Medicina Tropical 19:157-160, Jul-Set, 1986

outro sem anticoagulante. A seguir fez-se a determinação da hemoglobina e da atividade colinesterásica no sangue total e no plasma obtido por centrifugação a $3000 \mathrm{rmm}$ durante 10 minutos. No soro fez-se a determinação dos niveis de albumina e em alguns casos a eletroforese de protzinas com o objetivo de afastar tanto o comprometimento da sintese hepática de proteinas como hipoproteinemia carencial nos grupos estudados.

\section{Determinaçào da atividade colinesterásica}

A determinação da atividade colinesterásica baseou-se no método de Ellman e cols ${ }^{7}$. Os reagentes, com exceção do sulfato de quinidina, foram de procedência Boehringer GMBD Diagnóstica (Cat. no 15.984). As absorbâncias foram medidas com espectrofotômetro Bausch-Lomb, modelo Spectronic 88.

\section{Método para dosagem de colinesterase em eritrócitos}

Em 3,0 ml de tampão fosfato $50 \mathrm{mM}, \mathrm{pH}=7,2$, contendo ácido 5,5' - ditiobis-nitrobenzóico $0,25 \mathrm{mM}$, adicionou-se $10 \mu \mathrm{l}$ de sangue total e $10 \mu \mathrm{l}$ de sulfato de quinidina $0,1 \%$ (inibidor da colinesterase plasmática). Após agitação cuidadosa, adicionou-se $100 \mu \mathrm{l}$ de iodeto de acetilcolina $5 \mathrm{mM}$, misturou-se por agitação e mediu-se a absorbância em $412 \mathrm{~nm}$, a $25^{\circ} \mathrm{C}$ em intervalos de 1 minuto. Realizou-se 4 leituras em 4 intervalos consecutivos.

A atividade da enzima foi calculada de acordo com a equação:

$$
\mathrm{a}=\Delta \mathrm{A} \times 22,94 \times 10^{3} \mu \mathrm{moles} /(\min \times \mathrm{Hb})
$$

onde: $\Delta A=$ variação de absorbância e $\mathrm{Hb}=$ hemoblogina em $g / L$. Os resultados foram expressos em $\mathrm{UI} / \mathbf{g} \mathbf{H b}$.

\section{Método para dosagem de colinesterase no plasma}

Em 3,0 ml de tampão fosfato $50 \mathrm{mM}, \mathrm{pH}=7,2$, contendo ácido 5,5 - ditiobis-nitrobenzóico $0,25 \mathrm{mM}$, adicionou-se $20 \mu \mathrm{l}$ de plasma. A seguir adicionou-se $100 \mu \mathrm{l}$ de iodeto de acetilcolina $5 \mathrm{mM}$, misturou-se por agitação cuidadosa e mediu-se a absorbância em $412 \mathrm{~nm}$, a $25^{\circ} \mathrm{C}$ em intervalos de 1 minuto. Realizouse 4 leituras em 4 intervalos consecutivos.

A atividade da enzima foi calculada de acordo com a equação:

$$
a=\Delta \mathrm{A} \times 11,47 \times 10^{3} \mu \text { moles } /(\min \times \mathrm{L})
$$

onde: $\Delta \mathbf{A}=$ variação de absorbância. Os resultados foram expressos em UI/L.

\section{Análise estatistica}

Os resultados observados nos grupos de pacientes chagásicos foram analisados em relação ao grupo controle, pelo teste $\mathrm{t}$ de Student ao nivel de $5 \%$ de significância.

\section{RESULTADOS}

Os valores da atividade colinesterásica no plasna e em eritrócitos de individuos controles e dos pacientes chagásicos são mostrados na Figura 1 e Tabela 1.

As médias e os desvios padrões das atividades colinesterásicas no plasma e em eritrócitos do grupo controle foram: $2196 \pm 442 \mathrm{UI} / \mathrm{L}$ e $19,4 \pm 3,3 \mathrm{UI} / \mathrm{g} \mathrm{Hb}$ respectivamente. Os valores encontrados para os grupos de chagásicos foram: $2291 \pm 317 \mathrm{UI} / \mathrm{L}$ no plasma e 19,2 $\pm 3,7 \mathrm{UI} / \mathrm{g} \mathrm{Hb}$ em eritrócitos de portadores de cardiopatia chagásica com insuficiência cardiaca congestiva compensada; $2445 \pm 357 \mathrm{UI} / \mathrm{L}$ no plasma e $18,3 \pm 3,0 \mathrm{UI} / \mathrm{g} \mathrm{Hb}$ em eritrócitos de portadores de cardiopatia chagásica sem insuficiência cardiaca congestiva e $2006 \pm 327 \mathrm{UI} / \mathrm{L}$ no plasma e $17,8 \pm 3,1 \mathrm{UI} / \mathrm{g} \mathrm{Hb}$ em eritrócitos de chagásicos com a forma indeterminada.

A análise estatística não mostrou diferença entre os grupos de chagásicos crônicos e o grupo controle

\section{DISCUSSÃO}

Os achados de comprometimento de neurônios e das células de Schwann do colo observados por Tafuri 15 estão em concordância com os resultados obtidos por Hial e cols ${ }^{8}$, que mostraram significativa redução da atividade colinesterásica no plasma e em eritrócitos de individuos com megacolo chagásico.

Por outro lado, como mostra o presente trabalho, nas formas crônicas cardiaca e indeterminada da doença de Chagas, as atividades colinesterásicas plasmática e eritrocitária não se mostraram alteradas quando comparadas com aquelas do grupo controle normal.

Segundo Köberle ${ }^{10}$, a principal causa das alterações cardiacas na doença de Chagas crônica é a destruição de neurônios parassimpáticos intracardíacos. Lopes 12 observou que chagásicos que tiveram vida aparentemente normal e que morreram por acidente (atropelamento, homicídio, etc.) apresentavam despopulação neuronal cardiaca importante. Para Almeida e cols ${ }^{12}$ a insuficiência cardiaca congestiva no chagásico crônico depende basicamente da miocardite crônica e não da desnervação.

Nossos dados mostram que o comprometimento neuronal que ocorre nos cardiopatas chagásicos crônicos não leva a alterações significativas das atividades colinesterásicas no plasma e em eritrócitos. Provavelmente, este comprometimento não é suficientemente intenso a fim de levar a alterações enzimáticas 
Gomes RAS, Miziara LJ, Gonçalves JGF, Franchini KG, Hial V. Atividade colinesterásica no plasma e em eritrócitos de pacientes com as formas cardiaca e indeterminada da doença de Chagas. Revista da Sociedade Brasileira de Medicina Tropical 19:157-160, Jul-Set, 1986

detectáveis pelo método bioquimico empregado neste trabalho.

Entretanto, usando metodologias semelhantes na dosagem enzimática, os resultados quando comparados aos de Boston e cols ${ }^{34} \mathrm{e} \mathrm{Hial} \mathrm{e} \mathrm{cols}{ }^{8}$ permitem estabelecer diferenças entre megacolo chagásico, megacolo congênito e chagásicos crônicos não portadores de "megas".

Assim sendo, a atividade colinesterásica no plasma e em eritrócitos está diminuida em pacientes com megacolo chagásico, aumentada em pacientes com doença de Hirschsprung e inalterada em pacientes com formas cardiaca e indeterminada da doença de Chagas.

\section{SUMMARY}

Cholinesterase activity was measured in the plasma and erythrocytes from 10 healthy individuals and 26 chronic chagasic patients. The chronic chagasic patients were distributed in 3 groups: 6 chagasic patients with compensated heart failure; 10 chagasic patients with cardiopathy but without heart failure; and 10 chagasic patients with the indeterminate form. The enzymatic levels achieved in plasma and erythrocytes were. respectively: $2,196 \pm 442 \mathrm{UI} / \mathrm{L}$ and $19.4 \pm 3.3 \mathrm{UI} / \mathrm{g} \mathrm{Hb}$ from controls; 2,291 $\pm 317 \mathrm{UI} / \mathrm{L}$ and $19.2 \pm 3.7 \mathrm{UI} / \mathrm{g} \mathrm{Hb}$ from chagasic patients with compensated heart failure; $2,445 \pm 357 \mathrm{UI} / \mathrm{L}$ and $18.3 \pm 3.0 \mathrm{UI} / \mathrm{g} \mathrm{Hb}$ from chagasic patients with cardiopathy but without heart failure and 2,006 $\pm 327 \mathrm{UI} / \mathrm{L}$ and $17.8 \pm 3.1$ UI/g Hb from chagasic patients with the indeterminate form.

Our data show that neuronal injury in the cinronic cardiopathy is not sufficient to promote significant alterations $(p>0,05)$ in the cholinesterase activity in the plasma and erythrocytes.

Key words: Cholinesterase activity. Chagas disease. Chagasic cardiopathy. Indeterminate form.

\section{REFERÊNCIAS BIBLIOGRÁFICAS}

1. Almeida HO. A cardiopatia em chagásicos crônicos com e sem "megas". Tese para Professor Titular, Faculdade de Medicina do Triângulo Mineiro, Uberaba, MG, 1982.

2. Almeida HO, Teixeira VPA, Gobbi H, Rocha A, Brandão MC. Inflamação associada a células musculares cardiacas parasitadas pelo Trypanosoma cruzi em chagásicos crônicos. Arquivos Brasileiros de Cardiologia 42: 183-186, 1984.
3. Boston VE, Dale G, Riley KWA. Diagnosis of Hirschsprung's disease by quantitative biochemical assay of acetylcholinesterase in rectal tissue. Lancet 2: 951-953, 1975.

4. Boston VE, Cywes S, Davies MRQ. Serum and erythrocyte acetylcholinesterase activity in Hirschsprung's disease. Journal of Pediatric Surgery 13: 407-410, 1978.

5. Brown SS, Kalow W, Whittaker M, Woronick CL. The plasma cholinesterases: a new perspective. Advances in Clinical Chemistry 22: 1-123, 1981.

6. Siqueira ME, Fernicola NAGG, Borges EL. Determinação de níveis normais de colinesterase plasmática e eritrocitária. Revista de Saúde Pública da Faculdade de Saúde Pública Universidade de São Paulo 12: 340-344, 1978.

7. Ellman GL, Courtney KD, Andres JRV, Featherstone RM. A new rapid colorimetric determination of acetylcholinesterase activity. Biochemical Pharmacology 7: 88-95, 1961 .

8. Hial V, Ulhôa JP, Reis VF, Gomes RAS, Perez AC. Atividade colinesterásica no plasma e em eritrócitos de portadores de megacolo chagásico. Revista da Sociedade Brasileira de Medicina Tropical 16: 41-45, 1983.

9. Junqueira Jr LF, Gallo Jr L, Manço JC, Marin Neto, JA, Amorim DS. Subtle cardiac autonomic impairment in Chagas' disease detected by baroreflex sensitivity testing. Brazilian Journal of Medical and Biological Research, 18: 171-178, 1985.

10. Köberle F. Die Chagaskrankheit: eine erkrankung der neurovegetativen peripherie. Wiener Klinische Wochenschrift 68: 333-339, 1956.

11. Lemberg A, Macchi MC. Usefulness of serum pseudocholinesterase isoenzymes in acute and chronic liver diseases and neoplasms (experimental and clinical study). Acta Gastroenterológica Latinoamericana 11: 125-132, 1981.

12. Lopes ER. Estudo comparativo dos gânglios subepicárdicos nas cardiopatias shagásica crônica, reumática e hipertensiva. Tese para Docência-Livre de Patologia, Faculdade de Medicina do Triângulo Mineiro, Uberaba, MG, 1969.

13. Magris D, Mottola A, Mian G, Minutillo S, Trolo L, D'Agnolo N. Diagnostic and prognostic significance of cholinesterase (CHE) in chronic liver disease. Minerva Medica 70: 483-487, 1979.

14. Sportiello V, Pace M, Fernandes D, Stefan C. Serum levels of CHE (Pseudocholinesterase) in alcoholic cirrhosis patients. Correlation with the extent of anatomofunctional damage: unfavourable prognosis. Archivio per le Scienze Mediche 138: 307-313, 1981.

15. Tafuri WL. Alterações ultra-estruturais dos componentes muscular, intersticial e nervoso do coração e intestinos, na doença de Chagas experimental e humana. Tese para Professor Titular, Universidade Federal de Minas Gerais, Belo Horizonte, MG, 1974. 